\title{
Observation Codes to Evaluate Interpersonal Skills in Healthcare Students in a Mexican University
}

\author{
Salas-Medina, Daniela Lizbeth ${ }^{1}$, Martínez-Martínez, Kalina Isela ${ }^{2}$, Méndez- $^{-}$ \\ Puga, Ana María ${ }^{3}$, Sahagún-Padilla, Miguel Ángel ${ }^{4}$ \\ ${ }^{I}$ (Nursing, University of Nayarit, México) \\ ${ }^{2}$ (Psychology, University of Aguascalientes, México) \\ ${ }_{3}^{3}$ (Psychology, Michoacan University of San Nicolás de Hidalgo, México) \\ ${ }^{4}$ (Psychology, University of Aguascalientes, México)
}

\begin{abstract}
Interpersonal skills are fundamental for the healthcare students, as they need them for their daily practice interacting with patients and colleagues. Unfortunately, the interpersonal skills are not considered part of the evaluation in their formative years, and higher levels focus on theoretical and procedures leaving the student to develop those skills by itself. This article features a proposal to integrate the interpersonal skills in the university classrooms, using observation codes as a method to help delimit and evaluate interpersonal skills to have a foundation and analyze the changes needed in the Mexican educational system.
\end{abstract}

Keywords: Healthcare students, interpersonal Skills, Observation Codes.

\section{INTRODUCTION}

Teaching interpersonal skills to students in the healthcare area is complex as the concepts and procedures for clinical training take priority; the students then are not prepared for the real scenario where they will interact with patients. According to CONAMED (the commission in charge of investigating irregularities in healthcare attention in Mexico), many of the conflicts between health personnel and patients are precisely because of the lack of Interpersonal Skills (IPS), having misunderstandings and duplicating the work, as they fail at effective communication [1].

However, the problem comes from the training; Graduates from the healthcare area don't have the skills necessary to interact with patients, lacking adequate training in IPS. They are not ready for the different scenarios that may occur according to the sociocultural context [2]. The expectations placed on professionals in healthcare are not only in terms of knowledge about diseases and treatments, but in how they interact with patients and how they manage the conflict. Having good interpersonal skills allow solving problems effectively, avoid disagreements with patients and in general the hospital environment is less tense [3].

In Mexico, one of the problems in the training of the students in healthcare is that the IPS are not considered part of the evaluation; This because it is believed that these skills were already acquired in earlier educational levels, so the focus is the concepts and practical procedures, worrying about the IPS when a serious problem occurs in clinical practice and risks the student's academic future. In addition, students do not have a safe space where they can practice these IPS with adequate feedback.

Teachers argue that the time given to teach the class is short and the groups have 60 students or more. Still, one of the major flaws in the Mexican educational system is quantifying knowledge with a grade, reducing the learning process to a punishment or reward structure, as students with the best grades have facilities in choosing their schedule and teachers. Then not only the teachers don't care about the acquisition of IPS, but the students themselves ignore its relevance since the IPS are not considered for their average [4].

Other countries have emphasized the need to integrate the IPS in the education of the students in the healthcare area since they must maintain control in stressful situations responding in an appropriate way. They need to be trained properly so that they can attend patients and cope with the workload of the hospital [5].

Options were analyzed to implement an initiative of evaluation of IPS that are aligned to the theoretical contents of the subjects and at the same time will help the teachers to find points of improvement in students. Since most of the work in the classroom is in teams, this is an opportunity to see their interactions and register their IPS through observation codes and with those results work on the IPS that students still do not acquire.

Nevertheless, even though the proposal was interesting, there was a crucial problem that had not been considered; The students in the healthcare area do not take classes together. For example, only nursing students take classes in the nursing building, so they do not have training with other disciplines to work those IPS for the benefit of the patient. 
This lead to planning a pilot project during a regular semester, where students in the healthcare area took a class together on Saturday, aiming to not only see how the observation codes worked, but also to analyze the results to make a proposal for the students from different areas to take classes together, so they would interact as they will do so in the hospital.

The purpose of this pilot project is to make a proposal to integrate the codes of observation as a part of the evaluation of the students, as well as the importance of sharing learning space with healthcare classmates. Then their interactions will be as real as possible to the context in which they will develop.

\section{INTERPERSONAL SKILLS}

Students in healthcare should, during their training, acquire competencies that will allow them to respond to the needs that society demands. These skills include the interpersonal skills since patient satisfaction is an indicator of the quality of care, and healthcare professionals are in direct contact with patients. The patient's satisfaction then is influenced in how the interactions with the healthcare personnel are perceived [6].

The IPS focus in what the person needs to develop to have successful interactions; however, depending on the career, those IPS can change. An engineer will need IPS that can differ of those needed by healthcare students; This article centers on the IPS required in the healthcare area.

2.1 Definition of Interpersonal Skills

Since interpersonal skills are put into practice with other people, they can be defined as those that allow to establish social relations with clear parameters of interaction, with cordiality and respect. Lacking these skills can form barriers in the communication [7].

The IPS mark guidelines on communication between individuals; Since each person has a point of view influenced by prior experiences and cultural environment, it is natural that conflict arises. The IPS enable that those struggles are handled properly, mediating the differences and avoiding the conflict to scale.

The IPS can respond to a social situation and allow an enjoyable work environment and professional development, as well as a better performance in daily activities [8]. They have attitudinal, behavioral and cognitive components, and knowledge of social customs is needed to fix mistakes that may appear in the interaction.

The IPS are built throughout life, and create a positive environment, with confidence and facing challenges. They are tools that allow to adapt to social groups and at the same time give feedback for continuous learning. The IPS are constantly acquired, so those who have not developed them can learn [9].

The IPS let effective interactions and are abilities valued by employees, so it is necessary that they are learned or reinforced at college; however, the educational model focuses more on learning terms and techniques, and leaves the student in charge of the interpersonal skills on their own. In the healthcare area, students do not have a clear idea of what are these skills, or sometimes believe erroneously they already have them, facing problems at the hospital with nobody to guide them.

That is why defining the basic interpersonal skills needed in the healthcare is the first thing it should be clear, then delimit behaviors that show if that IPS is already learned, which will allow to suggest learning strategies that ease their acquisition.

\subsection{IPS needed in healthcare students}

As mentioned before, each area of learning has unique needs, and that includes which IPS are proper to perform in an ideal way. Healthcare students not only are in direct contact with patients, but also must work in multidisciplinary teams that are effective and at the same time work with the different shifts covered at a hospital to give the holistic care and quality that users demand.

One of the basic interpersonal skills is effective communication. This means using verbal and nonverbal channels and having a consistency in the message. It implies to be clear about what you want to communicate, use words suitable to the context and hear what others say. There should be feedback to make sure that the message is understood and expressing ideas without fearing repercussions; another basic skill is handling the conflict, as this emerges naturally when working with other individuals; learning to negotiate without losing the goal is a skill necessary to manage the difficulties that arise in the healthcare attention. Providing different alternatives of solution will allow an integration of the multidisciplinary team, which will give the patient a bigger picture about the situation and aid the process [10].

Effective communication is important since the student will establish different social relations (cultural, religious and socio-economic, to name a few), and the policies of health in Mexico have been directed in recent years to a multidisciplinary work. The Official Mexican Norm (NOM by the Spanish acronym) for the integral treatment of overweight and obesity marks precisely the multidisciplinary intervention in the follow-up of patients, requiring a commitment to this process for the benefit of the users of the systems of health [11].

The conflict management involves not only solving problems, but face them at a suitable time for an ideal solution. Conflict should not be avoided, or pretend it does not exist; It is something natural in the interactions, and acquiring this skill gives tools to keep a cordiality and reach agreements. 
These two interpersonal skills must be acquired by students in healthcare, as they allow a collaborative relationship through the clarification of the role, and at the same time they can help develop other complex skills such as empathy [12].

2.3 How to measure the IPS

The IPS are invaluable throughout the learning process; Incorporating them into classrooms influences the development of the student, and at the same time integrates the joining of the theory and the practice.Literature suggests different ways of developing tools that help the measurement of the IPS, particularly in the healthcare area. The most common is the checklist since it an easy option in the preferences in observation; it offers dichotomous responses, then only focuses on whether the action took place or not. At the same time, there are no interpretations regarding the conduct [13].

An example of a checklist, and one of the most used in the healthcare area is the SEGUE framework. SEGUE is an acronym which means ' Set the stage', ' Elicit information', ' Give information', ' Understand the patient's perspective' and ' End the encounter'. It has 25 items of 'yes/no', designed to help communication skills [14]. Another instrument that assesses the IPS is a survey to patients, so the user evaluates the skills of healthcare staff; It removes a limitation of the checklists, where there is only an observer who interprets the information. In this case, there will not be a third actor involved in understanding the feelings of the patient, as the patient itself answers the survey.

The instrument chosen for this pilot project was different of those described in previous paragraphs, giving different options to what the literature suggests: observation codes. Since it is intended to use within the classroom, the ideal setting is that the instrument can be used by the teacher. It's more complicated, but at the same time it is a little deeper than a checklist. The observation codes organize behaviors into categories that allow to offer an overview of the situation and its evolution, considering strategies that could be implemented afterwards.

\section{OBSERVATION CODES}

When the observation is used in the research as part of the method, you must meet certain requirements to be valid; such as having clear what phenomenon you want to observe, in whom, and when. Delimit what is wanted when observation is applied as instrument and how the data will be collected is important to a good analysis of the results, and the interpretation is maintained within the learning objectives. When behaviors are observed, there are many interesting facts that may seem relevant, but are not, therefore, to create codes of observation, specific behaviors are described, allowing consistency with what is sought to achieve.

This, of course, must be backed by a theoretical framework that establishes what you want to measure to operationalize the process [15]. Once defining the behaviors needed to observe, the instrument is built to make the method accurate and easy to use.

The pilot project considered two IPS: effective communication and conflict resolution to create categories which delimited the behaviors to observe in the students.

3.1 Categories and codes

There were four categories in total, covering the possible behaviors of students. Each category has its own description. The behaviors that can occur at any time during the interactions, are integrated in the category 'in general'.

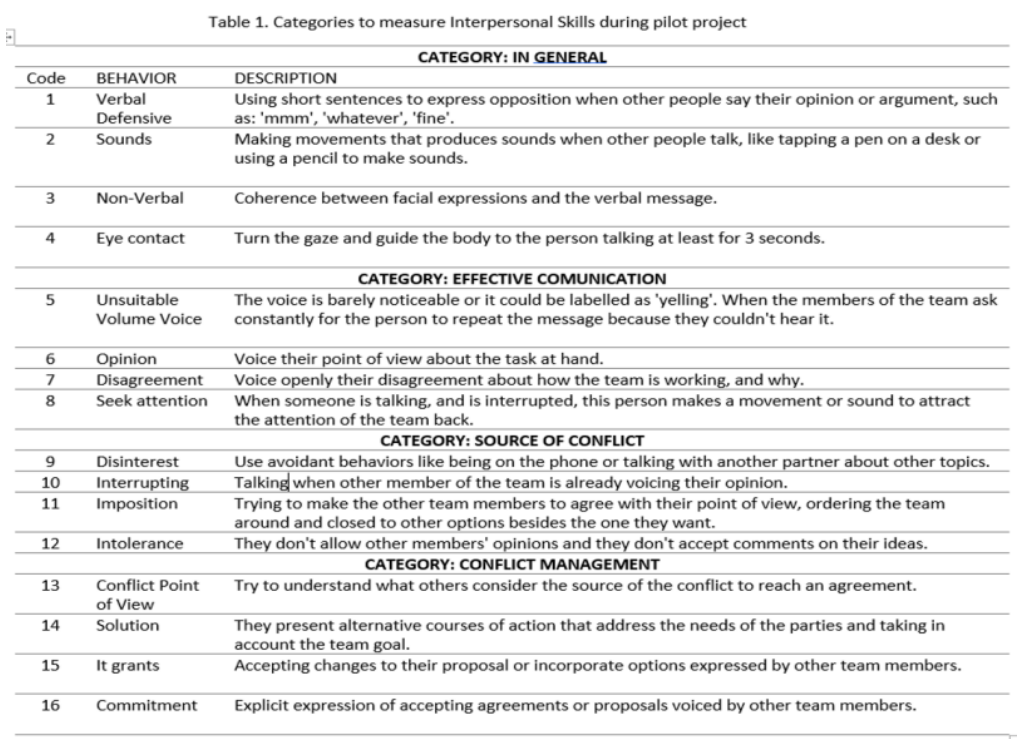


Behaviors that enable the dialogue properly, and ideas can be exchanged in a respectful manner and with a clear perspective, giving feedback are categorized as 'effective communication'.

In the category of 'source of conflict', behaviors registered are those that incite discussions, with differences between the students that prevent proper communication.

Resolving differences during the interactions and facilitating reaching agreements were into the category of 'conflict management'.

Each category has specific behaviors to observe; Table 1 shows each category and behaviors with the description to ease the training.

Once the instrument was designed, the validation process started, with filmed videos of students in previous classes, having the consent of the institution and the people involved since the pilot project is part of an investigation by the University.

3.2 Validation of the instrument

When the categories were defined, the instrument was subjected to an expert judgment with nine teachers in the healthcare area; In general, the instrument had good acceptance by judges, seven (78\%) agreed with the categories, while two (22\%) gave suggestions about examples in the code and add the category of 'other' for relevant behaviors not gathered under the classifications already established.

The Cohen's kappa coefficient was also a method to validate the instrument. It consisted in seeing cohesion and differences in what was observed, to see the contrast in a confusion matrix. Two observers (Psychologists) were trained from Monday to Friday in three-hour periods during a month.

Observers were trained in the categories, explaining in detail each one and clarifying the doubts that emerged in regard of the behavior to observe. Film videos where students work as a team, allowed that the observers could see exemplified the behaviors for differentiation and they memorized the numbers corresponding to each conduct to fill a registry sheet.

It was suggested using abbreviations when the filling the sheets, however, observers were hampered in remembering the abbreviations for each behavior, and found much more manageable memorizing the number of the conduct. This was also seen as advantage, as any outsider could not decipher what the numbers meant.

During the first three weeks, each behavior and category was discussed in detail; The material was observed independently, where commonalities and differences were compared. Then the same video was used, but with observers gathered together to discuss which was the perception in the differences that emerged.

Once the training was completed, the observers analyzed separately another film video, where students of nursing and medicine of the University of Nayarit worked in teams performing different activities; then they filled the observation's guide (Fig 1) allowing to register behavior in the minute and second it happened.

\begin{tabular}{|c|c|c|c|c|c|c|c|c|c|c|c|c|}
\hline \multirow[b]{2}{*}{ Minutes } & \multicolumn{12}{|c|}{ SECONDS } \\
\hline & $0-5$ & $\begin{array}{l}5 \\
10\end{array}$ & $\begin{array}{l}11 \\
15\end{array}$ & \begin{tabular}{|ll}
16 & - \\
20 & -
\end{tabular} & $\begin{array}{l}21- \\
25\end{array}$ & $\begin{array}{l}26 \\
30\end{array}$ & $\begin{array}{ll}31 & - \\
35 & \end{array}$ & $\begin{array}{ll}36 & - \\
40\end{array}$ & $\begin{array}{ll}41 & - \\
45\end{array}$ & $\begin{array}{l}46 \\
50\end{array}$ & $\begin{array}{l}51 \\
55\end{array}$ & $\begin{array}{l}56- \\
60\end{array}$ \\
\hline 0 & & & & & & & & & & & & \\
\hline 1 & & & & & & & & & & & & \\
\hline 2 & & & & & & & & & & & & \\
\hline 3 & & & & & & & & & & & & \\
\hline 4 & & & & & & & & & & & & \\
\hline 5 & & & & & & & & & & & & \\
\hline 6 & & & & & & & & & & & & \\
\hline 7 & & & & & & & & & & & & \\
\hline 8 & & & & & & & & & & & & \\
\hline 9 & & & & & & & & & & & & \\
\hline 10 & & & & & & & & & & & & \\
\hline
\end{tabular}

figure 1. observation's guide to register behaviors

Observers had a 94\% of concordance (169 observed behaviors, agreed in 159); something that the kappa coefficient calculates is how many of these coincidences may occur randomly, i.e. by simple chance. So, with those matches, the proportion of concordance (Por) was calculated, being 0.94, and the proportion expected by chance $(\mathrm{Pc})$ was 0.09730 . The observation codes had a Kappa coefficient of 0.93, which was considered valid and could be used in the pilot project [16]. 


\section{Pilot Project}

When the instrument was validated, the University authorized to carry out the pilot project in collaboration with the Academy of Health Psychology; since one of the main interests of the Academy is the interprofessional education, it was agreed that it could also open the opportunity to start mixed groups in the healthcare area to direct the model to a multidisciplinary approach.

The pilot project was also explained to the professors of the class in a meeting, adding the purpose of it, as well as explain that sessions were going to be filmed to make subsequent analysis; all teachers agreed that the classes could be filmed and agreed in having an observer in the class, but it would only be in a passive role where no interaction with the students was allowed [17].

The written consent from the students was obtained in the first class of the semester, and it was also an opportunity to answer any questions they had; mostly, the students agreed on how the pilot project would take place, and their only concern was if it was going to affect their grade, making clear that it was not the case.

The pilot project considered ethical aspects regarding the welfare of the participants, as well as their dignity; it was explained to the participants the objective of carrying out this pilot project, stressing how the information would be processed, with respect to whom declined to take part without exerting any kind of pressure or coercion. It also emphasized respect for the privacy of the students, and the names or videos never would be used in a public way, just as analysis of information to present results. Of 165 students taking the health psychology class, a sample of 108 was taken, divided into 18 teams of six members each.

Teams were formed randomly, regardless of gender or career; team activities began in October, so observers were integrated into the class in September, to see how long students adapted to the outsiders in the class. Although at the beginning, students tended to direct their attention to the observers and the camera, as they performed the activities they focused on the goal, and stopped worrying about being filmed.

\section{RESULTS}

One of the difficulties presented was filling the sheets since when observers saw the videos, they could pause or rewind sections to watch the behavior again, and in the class, it was challenging making the registry in real-time. Then, when analyzing the videos, the observers noticed that they ignored several behaviors that were generating conflict.

In the sheets filled in the classroom, there were approximately 70 behaviors per session, but when the video was analyzed, this amount increased to 156 , so more than half of the behaviors were unregistered by observers, until they had the access to the videos and they could stop or rewind the video to their needs.

This leads to a reflection on whether this is what happens in classrooms commonly; observing becomes a full-time task, but teachers also need to share their knowledge and make sure that the topics are covered properly. Perhaps it is why there is resistance by teachers to include interpersonal skills in the evaluations since they consider that they should be already acquired and is a waste of time to spend time in the classroom to teach them, when there are other priorities to attend to.

However, according to the registry sheet, this is also a priority. Five sessions were registered with the observation codes, and many behaviors aimed at the generation of conflict were presented, with just a few encouraging an effective communication.

Students did not have any problems to express their opinion; however, they are constantly interrupted so others can express their ideas, without letting others finish. This caused to avoid hearing the different points of view and just letting one person decides the course of action (Fig 2). There were often differences between them, and each member of the team provided what their profession should do in a situation, but it was clear that most of the students ignored what their teammate could do. It was more an imposition than a dialogue, ending in a division of tasks that left dissatisfied to more than one member on the team. Many ideas were not completed, and were acting based on outages, for example, if a student wanted to make a poster, another interrupted to give a color of letters, then the rest of the team began to perform the activity.

Also, conflict management behaviors were infrequent, and it did not have an impact on the interactions in general. The students were distracted with the cell phone, sometimes they forgot to make eye contact their peers when expressing their views, and sometimes distracted other teammates. In a session, some students were doing homework from a different class instead of working with the team, leaving others to decide what to do and just following directions (Fig 2).

It is clear then that students consider their interactions as something aimed at results, instead of being an interdependence between them to be able to integrate their skills and knowledge in performing the task. Their interpersonal skills and behaviors are focused to meet as required, assuming the division of tasks as ideal to avoid conflicts and simply comply. 


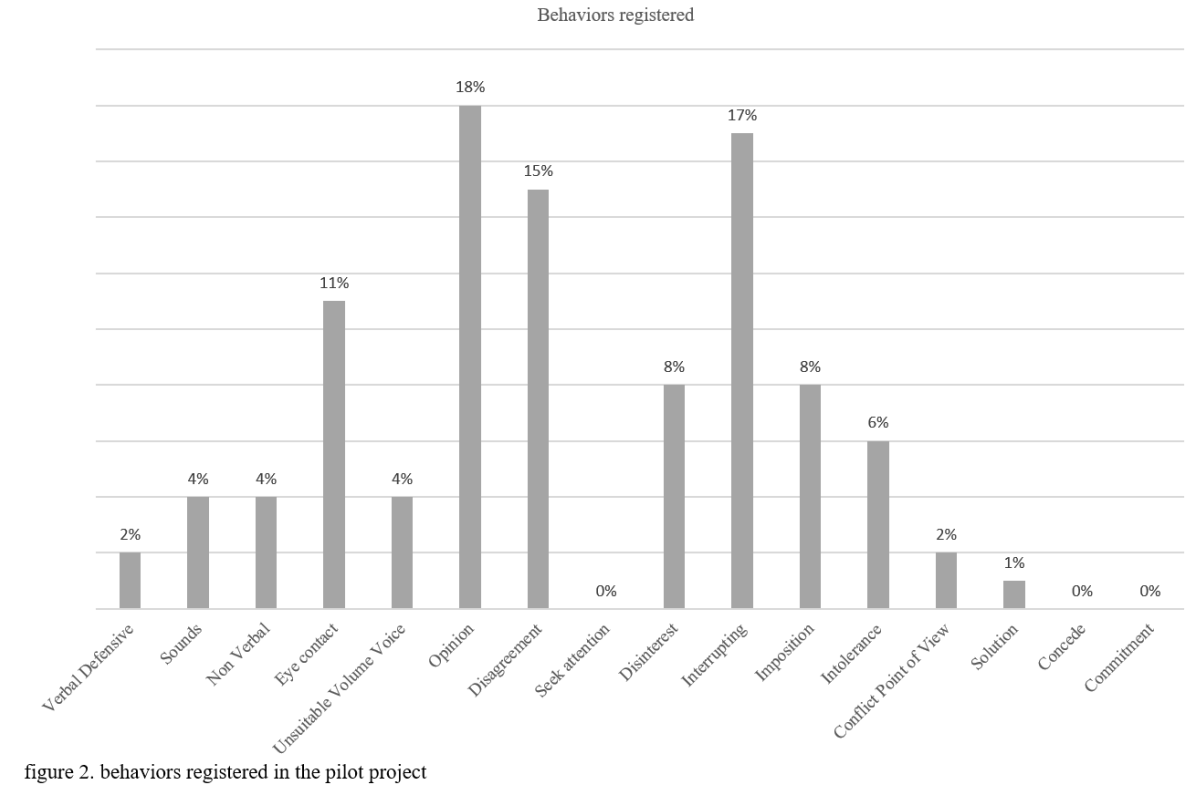

The observation codes showed that students do not have interpersonal skills since they do not communicate effectively, and when the conflict arises, they avoid it instead of handling it. It should be noted that students were concerned about these results thinking they could influence negatively on their grade, so when the transition is made and the IPS are integrated into the evaluation, the attitude that students will take in this regard should be considered since even they see the IPS as meaningless to evaluate them as part of their grade.

These results showed that the instrument still needs improvement. The pilot project exposed the shortcomings this application presented, and it allows plan another project to see if evaluating the IPS may be part of the activities in the classroom for the benefit of the student.

\section{CONCLUSION}

In recent years, emphasis has been given to the self-regulated learning, where the student can regulate its own learning optimally, is motivated managing the time properly [18]. In Mexican classrooms, this is still impossible since students are dependent on an education system where the teacher is in charge, and has the control, so the students leave the learning in the hands of these experts who order them what to do, how to do it and when to deliver it.

In this pilot project, the challenge was to record behaviors during the students' interactions; unfortunately, doing it with so much detail, minute and second it occurred, will not be the most ideal for teachers in the classroom. The professor cannot focus on teaching and registering behaviors at the same time since this pilot project showed behavior registration is somewhat complex and time-consuming.

A propitious time to conduct registration of the behaviors is when students work as a team since they not only have to interact with each other, but the teacher adopts a more passive role and can only focus to observe and record the behaviors. Even so, the instrument must be modified to be less laborious and allow professors to list the behaviors that students present.

However, another problem is what to do when students do not have the necessary IPS; i.e., the pilot showed that it only gives a diagnosis regarding the IPS, but after that diagnosis, how can the students acquire them? What the teachers need to do when this is the case? This is something that was not anticipated when the planning of the pilot project happened, and now with these results, this becomes a relevant issue.

We cannot integrate the IPS to the evaluation rubrics; if the student does not possess them, then it is the responsibility of the professor to teach them as part of the curriculum, and sometimes the professor does not have those IPS neither. This gives an opportunity for the next project, where not only the diagnosis of interpersonal skills is relevant, but also the designing of a method in which the students acquire and improve their IPS over the classes.

It is regrettable that the IPS, being important have been ignored for so long in Mexican educational systems. The country requires competent professionals, but it neglects the integral education by focusing only on concepts and procedures. This pilot project shows that it is important to begin to discuss strategies for students to finally have a full training in everything: knowledge, skills and attitudes that students should have when they graduate. 


\section{ACKNOWLEDGEMENTS}

Thank you to the mexican National Council for Science and Technology (CONACyT) for sponsoring this pilot project. Thanks to the University of Nayarit for giving the resources for the project. Thanks to Ana and Lucía for the support and the information.

\section{REFERENCES}

[1]. M. Luna, los diez principios básicos de las relaciones interpersonales en la atención médica (Mexico: CONAMED, 2008)

[2]. Mental Health Commission, multidisciplinary team working: from theory to practice (Irlanda: Dublin, 2006).

[3]. NG. Barakat, Interpersonal skills, Lybian J Med, 2(3), 2007, 152-153.

[4]. J. Rivas and J. Ruíz, ¿Control, castigo o premio en el otorgamiento de calificaciones? Contexto educativo: Revista digital de investigación y nuevas tecnologías, (29), 2004, 1-34.

[5]. S.H. Mastracci, M.A. Newman and M.E. Guy, Emotional labor: why and how to teach it, Journal of Public Affairs Education, 16(2), 2010, 123-141.

[6]. M. Samina, GJ. Qadri, SA. Tabish, M. Samiya and R. Riyaz, Patient's perception of nursing care at a large teaching hospital in India. International Journal of Health Sciences, 2(2), 2008, 92-100.

[7]. D. Duffy, G. Gordon, G. Whelan, K. Cole-Kelly and R. Frankel, Assessing competence in communication and interpersonal skills: the Kalamazoo II report. Academic Medicine, 79(6), 2004, 495-507.

[8]. K. Kraiger and S. Kirkpatrick, An empirical evaluation of three popular training programs to improve interpersonal skills. Journal of Psychological issues in Organizational Culture, 1(1), 2010, 60-73.

[9]. P. Wheeler, The importance of interpersonal skills. Emotional intelligence significantly impacts leadership success - and the bottom line. Healthcare executive, 20(1), 2005, 44-46.

[10]. N. Christie, An interpersonal skills learning taxonomy for program evaluation instructors. Journal of Public Affairs Education, 18(4), 2012, 739-756.

[11]. Diario Oficial de la Federación, Norma Oficial Mexicana NOM-008-SSA3-2010 para el tratamiento integral del sobrepeso y la obesidad (México: Diario Oficial de la Federación, 2010).

[12]. E. Suter, J. Arndt, N. Arthur, J. Parboosingh, E. Taylor and S. Deutschlander, Role understanding and effective communication as core competencies for collaborative practice. Journal of Interprofessional Care, 23(1), 2009, 41-51.

[13]. C. Hobgood, R. Riviello, N. Jouriles and G. Hamilton, Assessment of comunication and interpersonal skills competencies. ACAD EMERG MED, 9(11), 2002, 1257-1269.

[14]. G. Makoul, The SEGUE Framework for teaching and assessing communication skills. Patient Education and Counseling, 45(1), 2001, 23-24.

[15]. A. Lázaro, Procedimientos y técnicas del diagnóstico en educación. Tendencias Pedagógicas, 1(7), 2002, 97-116.

[16]. B. Gabín, O. Camerino, M.T. Anguera and M. Castañer, Lince: multiplatform sport analysis software. Procedia-Social and Behavioral Sciences, 46, 2012, 4692-4694.

[17]. G.E. Gorman and P. Clayton, Qualitive Research for the Information Professional: A Practical Handbook. (London: Facet Publishing, 2005)

[18]. M. Boekaerts, Self-regulated learning: A new concept embraced by researchers, policy makers, educators, teachers, and students. Learning and Instruction, 7(2), 1997, 161-186. 